\title{
Material e instrumentos ligados a la alimentación saharaui. Aspectos culturales, lingüísticos y semánticos
}

\author{
Material and Instruments Linked to the Saharawi Food. \\ Cultural, Linguistic and Semantic Elements
}

\author{
Moulay-Lahssan Baya E. \\ Departamento de Traducción e Interpretación \\ Universidad de Granada
}

\section{RESUMEN}

En este artículo, centrado en la región denominada Sáhara Occidental (antiguo Sáhara Español), y directamente relacionado con la dialectología y las tradiciones populares, ofrecemos un estudio sobre el material y los instrumentos culinarios utilizados tradicionalmente (aunque mucho de ello se conserva hoy en día) por los habitantes autóctonos de dicha región. Para ello, abordamos cuestiones principales tales como el dialecto hạssāniya; la cocción y preparación tradicional de los alimentos en la zona objeto de estudio; los instrumentos y vasijas para el tratamiento de la leche; los instrumentos para el tratamiento del grano o el uso y aprovechamiento de arbustos para la obtención de la madera, ya que la inmensa mayoría de los recipientes de madera se fabricaban a partir de algunas de las especies leñosas más representativas del entorno. El enfoque es, básicamente, antropológico, con un evidente componente semántico, reflejado en el uso abundante de terminología árabe - hassāniya, con su equivalente castellano.

Palabras clave: Dialecto ḥassāniya, Alimentación tradicional, Sáhara Occidental, Utillaje culinario, Arbustos autóctonos.

\section{SUMMARY}

This article focuses on the region called Western Sahara (former Spanish Sahara) and directly related to dialectology and folk traditions, we provide a study on the culinary equipment and instruments used once (although much of it remains today) by the indigenous inhabitants of the region. To this end, we address key issues such as Hassaniya dialect; cooking and food preparation in the traditional survey area; instruments and vessels for the treatment of milk; tools for treatment of grain or the use and utilization of shrubs for obtaining wood, since the vast majority of wooden containers were made of some of the most representative woody species in the area. The approach is basically anthropological, with obvious semantic component, reflected in the generous use of Arab-Hassaniya terminology, with its equivalent in Spanish.

Key words: Hassaniya Dialect, Traditional Food, Western Sahara, Culinary Equipment, Native Shrubs. 


\section{INTRODUCCIÓN}

El objetivo principal de este trabajo es intentar ofrecer una visión general del uso de los utensilios de la cocina tradicional saharaui que, a juzgar por la experiencia y los relatos de los más ancianos, no fueron del todo transcendentales, ya que todo el mundo prefería comer con la mano y beber del mismo recipiente, tal como lo siguen haciendo hoy en día muchos descendientes de aquellos nómadas. La investigación es fruto de los trabajos de campo realizados por el autor durante la elaboración de su tesis doctoral ${ }^{1}$ hace más de doce años y cuyos datos se han actualizado y complementado, ahora y a través de este ensayo, con información sobre algunos aspectos lingüísticos-semánticos ${ }^{2}$, que consideramos que ayudan a enriquecer este tipo de estudios.

Para beber líquidos y comer alimentos sólidos, los habitantes del Sáhara Occidental utilizaban, tradicionalmente, recipientes que se fabricaban de madera y, en algunos casos, de metal. Después de la instalación de algunos puestos comerciales en la zona, con la colonización del Territorio por los españoles, los recipientes metálicos y las cucharas de aluminio empiezan a ocupar el sitio dejado por los utensilios tradicionales. El grueso de la documentación presentada en este trabajo está basada en fuentes orales y ha sido conservada, hasta la fecha, por los más sabios de la región, sirviendo, en cierto modo, para contextualizar la alimentación practicada antaño, a través de un estudio comparativo con regiones limítrofes o, en algunos casos, con otras que presenten características similares, sobre todo, de naturaleza beduina o nómada ${ }^{3}$.

Las fuentes orales representan la aportación más valiosa de información para la historia de alimentos en el Sáhara Occidental en las últimas décadas. Las personas que viven en esta región conservan las técnicas utilizadas tradicionalmente por los beduinos y, por lo tanto, son fuente privilegiada de información. Sin embargo, la recopilación de datos plantea una serie de problemas metodológicos, principalmente relacionados con el tiempo y el espacio. La información facilitada se remonta, por lo general, a tres generaciones: las del informante, sus padres y sus abuelos. Este lapso de tiempo puede cubrir no más de setenta años, lo que limita la proyección histórica de la oralidad. En cuanto al espacio, los nómadas ofrecen datos diferentes en función de su ubicación geográfica, su afiliación tribal y, por último, la temporada del año en que el investigador les pide que respondan a las preguntas. Teniendo todo esto en cuenta, los informantes entrevistados para la elaboración de nuestro trabajo de campo

\footnotetext{
${ }^{1}$ Esta tesis, titulada El Sáhara Occidental: alimentación y cocina tradicional. Aspectos culturales, lingüisticos y etnobotánicos y dirigida por la Dra. Expiración García Sánchez, del Consejo Superior de Investigaciones Científicas (CSIC) de Granada, fue presentada en el Departamento de Estudios Semíticos de la Universidad de Granada en el año 2002, y constituye una especie de "tratado" en el que se entremezclaban varias disciplinas (alimentación, cocina, flora, fauna, dialecto, medicina tradicional, etc.).

${ }^{2}$ En este nuevo trabajo se han utilizado fundamentalmente estudios sobre la flora sahariana (Barrera et al. 2007; Volpato 2008), sobre el menaje de cocina, con un enfoque arqueológico (Lafuente 1996; Rosselló 1994; Marín 1999), y otros relacionados con el dialecto hassāniya (TaineCheikh 1988-1998; Ould Mohamed Baba 2008).

3 Sobre las fuentes para el estudio de la alimentación en el Sáhara Occidental, que pueden ser también aplicable a las zonas vecinas, en especial Mauritania y el sur de Marruecos, véase mi artículo (Baya 2004).
} 
pueden responder a los siguientes perfiles: personas con preparación (estudiosos, especializados en disciplinas clásicas, como literatura, el Corán, jurisprudencia islámica, etc.); mujeres y hombres comunes, generalmente sin preparación alguna. A la hora de seleccionar los informantes altamente preparados, la edad no suele suponer un factor decisivo y, generalmente, oscila entre 35 años, para los más jóvenes, y 80 años para los más viejos. Esta categoría de informantes se puede encontrar, fácilmente, entre miembros de grupos que afirman descender del Profeta Mahoma ( $\breve{o r f a) ~ o ~ e r u d i t o s ~}$ miembros de tribus zwālä o $a b l$ ləktūb, habitantes de la zona sur del Sáhara Occidental, que se dedican al estudio y a la meditación religiosa. Ejemplos de estas tribus son, entre otros, Ahl Aš-Šeij Mäl'aynīn, Ahl Bārikäl-lä o Täwbālət ${ }^{4}$. El segundo grupo lo integran mujeres y hombres comunes, que se sitúan también en la mismo grupo de edad que los anteriores y cuyas aportaciones a la hora de facilitar información sobre la alimentación y los instrumentos culinarios en la zona objeto de estudio han sido muy relevantes 5 .

Este material culinario tradicional ( $m m \bar{a}^{\top} \bar{i} n$, de $m \bar{a}^{-} \bar{u} n$ : utensilios de cocina) ${ }^{6}$ es el que vamos a dar a conocer en sus usos y aplicaciones más extendidas entre la población sahariana nómada.

\section{EL DIALECTO ÁRABE HASSĀNIYA}

\subsection{ORIGEN, HISTORIA Y CARACTERÍSTICAS}

No es nuestra intención ofrecer, en este apartado, un estudio exhaustivo sobre el dialecto árabe-magrebí hassāniya, más bien aspiramos a resaltar características que consideramos relevantes para la contextualización del tema principal de nuestro trabajo, es decir, el material y los instrumentos culinarios afines a la alimentación saharaui, y remitir, al mismo tiempo, a trabajos representativos y bien consolidados, dentro de la dialectología norteafricana (Oro Pulido 1940; Cohen 1963; Rennes-Taizin 1978; Ould Mohamed-Baba 1996, 1998, 2002, 2004, 2008; Taine-Cheikh 1978, 1988, 1989, 1997).

El dialecto árabe hassāniya es sumamente importante a la hora de realizar un estudio profundo sobre la alimentación en el Sáhara Occidental, ya que las distintas fuentes a las que podemos recurrir están escritas o documentadas oralmente en el mismo, lo cual dificulta enormemente el acceso a ese material sin un conocimiento amplio y preciso del campo semántico y lingüístico de dicha modalidad. El ḥassāniya, al igual que el resto de los dialectos pertenecientes a otras lenguas, tiene una lengua madre que lo acoge y le proporciona sus materiales lingüísticos básicos y generales: el árabe.

El dialecto hassāniya pertenece a los dialectos hilalíes, que llegaron con los Banū Hilāl (Banū Sulaym y Banū Ma'qil) y, a través de toda el África del Norte, entraron

\footnotetext{
${ }^{4}$ Véase Mulero Clemente (1945), para un trabajo exhaustivo sobre el origen de las tribus del antiguo Sáhara español, además de las características y la zona geográfica de cada una.

${ }^{5}$ En un trabajo anterior (Baya 2004) se ofrece información complementaria sobre tipo de fuentes, lugar, edad y sexo de los informantes consultados.

${ }^{6}$ Este término se utiliza más en plural. Brunot (1920: 135) hace un estudio exhaustivo sobre el mismo vocablo desde varios puntos de vista.
} 
finalmente en Marruecos en el siglo XII (Aguadé 2008: 282). El dialecto ḥassāniya, impuesto a partir del siglo XVII como medio de comunicación en todo el territorio de 'trāb al-bizân (tierra de los bizānn)', debe su nombre a las tribus de Banū Hassān, que se impusieron por la fuerza sobre las tribus Șanhâŷya (Ould Mohamed-Baba 2004: 147). Según algunos historiadores, este dialecto procede del Yemen, al igual que las tribus de la región (Hamdātī 1998: 18). De ahí la afirmación de que la música hassāñī, su literatura y su arte tienen fuertes vínculos comunes con los del Yemen y la gente de las dos regiones congenia y se entiende perfectamente. En este sentido, se puede aplicar el proverbio que reza "kullu šay yar y $\hat{y} i$ 'u ila așli-hi", o sea, "todo regresa a su origen", tanto si se trata de literatura, arte o lengua. En el caso de los saharauis, ello significa que tienen un origen étnico y lingüístico árabe puro, aunque hablen en dialecto ḥassā niya. Por lo tanto, el interlocutor u oyente, al escuchar a un saharaui o a un bïzāni hablando en hassāniya, se dará cuenta, aunque tenga un escaso conocimiento lingüístico de este dialecto, de que se trata de un dialecto o habla árabe ${ }^{8}$.

El étimo lingüístico (árabe o de otras lenguas) de algunos vocablos en hassāniya resulta, a veces, difícil de averiguar con exactitud, pese a que algunos son de clara procedencia bereber y, según varios estudiosos, representan un porcentaje muy alto, especialmente, en campos semánticos tales como la toponimia, la geografía, la terminología agrícola y ganadera, y la fitonimia (Ould Mohamed Baba 2004: 176; Colin 1930:141).

Los términos del hassāniya, expuestos y analizados en este trabajo, corresponden al dialecto hablado en el Sáhara Occidental, norte de Mauritania, además de la zona suroeste de Argelia, sur y sureste de Marruecos, en concreto Wād Nūn, y Mhāmīd el-Gizlān, y son, en su mayoría, del árabe, y el resto son también de esta misma lengua pero con ciertas deformaciones semánticas o lingüísticas. La lengua árabe constituye aproximadamente el 86\% del vocabulario del hassāniya. El resto proviene, en un porcentaje muy alto, del bereber y dariŷa marroquíes, y, en menor medida, de otras lenguas o dialectos, tales como el francés, español, wolof, pular, azēr, etc. (Ould Mohamed-Baba 1996: 147). El dialecto hassāniya, con mayor número de voces de origen bereber o șanhāŷy, puede ser la variedad hablada en la zona de al-Gəblä de Mauritania, si atendemos al número y diversidad de términos localizados y estudiados en esta región (Ould Mohamed-Baba 2004: 175)9.

${ }^{7}$ El término bìzānin o al-bīzān, o también trāb el-bīzān (la tierra de los bìzān, es decir, los grupos étnicos de raza caucásica entre los beduinos de la región), se refiere, generalmente, a los habitantes de Mauritania y el Sáhara Occidental, en oposición a la tierra de los negros o trāb essudān, con el que se denomina a los habitantes y los territorios de los países limítrofes que son negros. El significado del término bĩzānī (blanco o caucásico) sobrepasa la mera referencia étnica y alude a todo individuo o grupo social cuya etología y modo de vida son los mismos que los de los nómadas de origen árabe que conforman la mayoría de la población de la zona, incluyendo el conocimiento de los referentes culturales y de la poesía ḥassānī.

${ }^{8}$ Es de suma importancia el trabajo publicado por Ould Mohamed Baba (1998: 163-201). En él se detalla todo cuanto se refiere a la vida de los bizāan, la terminología ḩassānī, etc., y se centra en la zona de el-Gəblä que guarda estrecha relación, desde el punto de vista lingüístico, geográfico y cultural, con la región del Sáhara Occidental.

${ }_{9}^{9}$ En este artículo se ofrece valiosa información sobre la influencia del bereber en el hassāniya en esa zona de Mauritania y detalla, de forma exhaustiva, los campos semánticos más frecuentes (alimentos, animales, creencias, dinero, enfermedades, fenómenos atmosféricos, minerales, partes del cuerpo, plantas, tribus, utensilios, muebles, etc.). Ver también Baya (2007b). 
No obstante, las opiniones de los estudios acerca de la influencia del bereber en el árabe ḥassāniya suelen ser poco homogéneas y, en algunos casos, diametralmente opuestas, y esta situación la podemos encontrar también en cuanto a la uinfluencia e importancia del sustrato bereber en el árabe dialectal marroquí, ya que tal como afirma Aguadé (2008: 303): “... mientras que para algunos especialistas sería mínima, otros defienden la opinión contraria. Hay que tener en cuenta, sin embargo, que todavía no hay estudios detallados y completos acerca de esta cuestión. Y tampoco hay que olvidar que los resultados pueden variar significativamente según el tipo de dialecto estudiado". Esta situación puede ser parecida a la que existe hoy en día con el hassāniya, ya que la influencia y presencia del sustrato bereber puede ser mayor o menor en función de la zona objeto de estudio.

En definitiva, se puede decir que es un dialecto unitario con mínimas diferencias de una región a otra en cuanto a la pronunciación. Se le conoce también con el nombre de klām lo'räb (habla de los árabes). Y en esto hay que darles la razón a los estudiosos de las lenguas (Ṭāleb Būya 1999: 18), porque el hassāniya es la lengua árabe en su estado más puro e inicial y se diferencia de esta por la pronunciación de las palabras con apócope (sukūn) de su última vocal el: qāma $(g \bar{a} m)$, akala (kāl), qāla (gāl), etc.

\subsection{Sistema DE TRANSLITERACIÓN UTILIZADO EN ESTE TRABAJO}

Al no tratarse de un trabajo puramente gramatical, no pretendemos presentar un estudio exhaustivo sobre la transliteración de los sonidos del dialecto hassāniya. No obstante, con la finalidad de ordenar el material semántico expuesto en el artículo en aras a una mejor pronunciación e identificación de los términos en cuestión, aplicaremos grosso modo la transliteración propuesta por otros investigadores (Ould Mohamed-Baba 2008; Taine-Cheikh 1988-98).

Fonemas vocálicos:

/a/: breve, abierta, central. /ä/: breve, abierta, centro-anterior. /ā/: larga, abierta, central. /e/: breve, media, central. /i/: breve, cerrada, anterior. /îl: larga, cerrada, posterior. $/ \overline{\mathrm{u}} /$ : larga, cerrada, posterior. $/ \mathrm{\vartheta} /$ : breve, media, central.

Este último sonido vocálico (ə) es muy frecuente en el dialecto hassāniya y es difícil encontrar un fonema que lo represente con la máxima exactitud, ya que se trata de un sonido intermedio entre la 'a' y la 'e' breves, sin llegar a fundirse en ninguna de las dos. Se trata, más bien, de una vocal de timbre medio y, según las consonantes que la rodean, tiene el valor de una ' $e$ ' muda francesa o tiende hacia una (è) u (o) francesas abiertas. Se da con bastante frecuencia tanto en principio como en mitad de la palabra y también, aunque en menos casos, al final de algunos vocablos. En algunos trabajos anteriores, se ha utilizado la grafía /æ/ para representar fonéticamente dicho sonido (Baya 2007a).

Diptongos: /ay/, /äy/, /āy/, /aw/, /ow/, /ōw/, /iw/, /uw/.

Fonemas consonánticos ${ }^{10}: / /$ : (oclusiva glotal). /b/: (bilabial oclusiva sonora). /ḅ/: (bilabial oclusiva sonora enfática). / $\mathrm{y} /$ (labiodental fricativa sonora). /n/: (bilabial fri-

${ }^{10}$ El sonido consonántico /ğ-飞/ lo hemos transcrito en este trabajo por la /ŷ/, postura también propuesta por varios autores (Ould Mohamed-Baba 1996: 148). Otros sonidos, tales como 
cativa sonora enfática). /f/: (labiodental fricativa sorda). /m/: (bilabial nasal). /m /: (bilabial nasal enfática). /w/: (semiconsonante bilabial). /t/: (dental oclusiva sorda). /d/: (dental oclusiva sonora). / $\mathrm{d} /:$ (alveolar fricativa sonora). $/ \mathrm{z} /:$ : (alveolar fricativa sonora velarizada). /ṭ/: (dental oclusiva sorda enfática). /n/: (dental nasal). /ñ $/:$ (dental nasal palatalizada). /r/: (alveolar vibrante). /ṛ/: (alveolar vibrante enfática). /z/: (alvéolopredorsal sibilante sonora). /̌̌/: (alvéolo-predorsal sibilante sonora enfática). / $/ \mathrm{t} /$ : (interdental fricativa sorda). /ḍ/: (dental oclusiva sonora enfática). /s/ (predorsal sorda). /ṣ/: (predorsal sorda enfática). /š/: (africada sorda). /g/: (africada sonora). /y/: (semiconsonante prepalatal). $/ \mathrm{D}^{11} /$ : (prepalatal sonora). $/ \check{\mathrm{T}} /$ : (prepalatal sorda). /1/: (lateral). /1/: (lateral enfática). /k/: (postpalatal oclusiva sorda). /g/: (postpalatal oclusiva sonora). /q/: (velar oclusiva sorda). /j/: (velar fricativa sorda). $/ \mathrm{g} /:$ (velar fricativa sonora). $/ \%$ : (faringal fricativa sonora). $/ \mathrm{h} /$ : (faringal fricativa sorda). $/ \mathrm{h} /:$ (glotal fricativa). lzl: (silbante alvéolo-predorsal).

\section{COCCIÓN Y PREPARACIÓN}

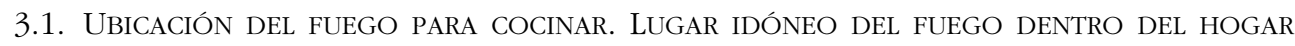
BEDUINO

Antes de pasar a hablar de los utensilios de la cocina tradicional saharaui o nwâla (Aguilera 2006: 13), convendría resaltar la importancia del fuego en la vida de los habitantes del Sáhara Occidental, en particular, y los pueblos árabes nómadas, en general. Dos son los elementos esenciales en el proceso de transformación de los alimentos crudos en cocidos: el fuego y los recipientes —aunque estos últimos no siempre son necesarios- (Marín 1999: 168). El fuego (en-nār) desempeña un papel de primer orden en la vida del beduino saharaui, y el lugar para su ubicación, tanto dentro de la jaima como fuera de ella, además de la calidad de la madera con que se enciende, no dejan de ser una constante preocupación para los nómadas.

Cuando los beduinos se disponen a instalarse en un punto del desierto, buscan un lugar idóneo para establecer su jaima y también un punto estratégico para la preparación del fuego. Normalmente, se localiza una sädrāyä ${ }^{12}$ (arbusto en general) que esté situado delante de el-jālfä es-sāḥliyä (viento anterior derecho), para proteger el fuego que se vaya a encender de las continuas rachas de viento, y se amontona suficiente leña (lohtäb) en su parte sur occidental para resguardarlo del aire que suele soplar de oeste y norte (es-sāḥliyä y et-tälliyä $)^{13}$. Esto es en lo que concierne al lugar del fuego

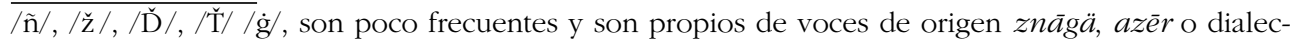
tos africanos (Ould Mohamed-Baba 1996: 147, 148; Cohen 1963: 21), y se reducen a campos semánticos muy particulares (toponimia, gastronomía, botánica, etc.); apenas los hemos utilizado en este trabajo.

${ }^{11}$ Este fonema, junto con la $/ \breve{T} / /$, los hemos representado en mayúscula, al no disponer el programa informático utilizado del mismo signo en su forma minúscula. No obstante, tal como hemos señalado en la nota de pie anterior, dichos fonemas son poco frecuentes y apenas aparecen en los vocablos recogidos.

${ }^{12}$ Este término también se conoce por sadra o sdar. Aguilera (2006: 7).

${ }^{13}$ Esta medida preventiva se toma solamente en el caso de que no sople viento del sur (lgəbliyä).
} 
permanente en la jaima. Sin embargo, el proceso cambia cuando se trata de un acontecimiento importante, tal como un 'íd (fiesta religiosa), 'ors (boda) o la visita de invitados ilustres, procedentes de un lugar lejano y que van a permanecer varios días en dicha morada; lo que requiere el sacrificio de camellos o cabras o la preparación de pan en hornos tradicionales alejados del hogar beduino tradicional. En este caso es imprescindible preparar el fuego en un lugar apartado de la tienda tradicional. Se suele hacer en una fädrä (arroyo que nace en terreno elevado), en un golfo (ej-lîy), un riachuelo (udey), cerca de un arbusto grande o entre arbustos no muy grandes para evitar eventuales y fuertes rachas de viento. No se debe acercar el fuego demasiado a estos árboles para permitir que le llegue suficiente aire para respirar y evitar que se apague. En cuanto al fuego que se enciende cerca de la jaima, esta debe estar orientada hacia el norte (em-gāfyä), es decir, tusäd-dər cuando sopla viento del sur (el-gəbliyä). En ese caso, se instala el fuego al abrigo de la jaima (dfä-l-jeymä), ya que se trata de un fuego provisional. Si sopla viento del oeste o poniente (s-sābliyä) se orienta la jaima

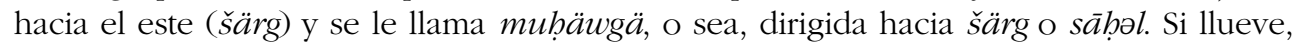
se coloca el fuego dentro de la jaima, cerca de la estera delantera para calentar la tienda, iluminarla con sus llamas y poder calentar el té, secar la ropa húmeda o simple-

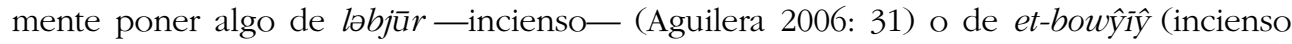
perfumado y quemado). De esta manera proporcionará calor a los que están dentro de la morada y evitará que los chaparrones que caen intensamente apaguen el fuego ${ }^{14}$. Para encender el fuego, se excava un hoyo no muy profundo ni tampoco muy ancho parar evitar que el viento alcance el núcleo de la llama y se rodea de tres fogones —mnāṣəb, sing. mänșäb- (M'Hamsadji 1955: 16) de piedras duras y resistentes (șuniyāt), difíciles de romperse por el contacto con el fuego ${ }^{15}$. Se suele excavar a su lado otro hoyo menos grande, donde se coloca algo de leña fina (jšäb), si se teme una eventual quema de la olla (märŷän) cuando el fuego original es intenso. Dicha leña, que se aparta, tiene también su importancia, ya que sirve para poner la tetera grande a hervir, extraer brasa —ềmär — (Aguilera 2006: 10) o asar algo de carne, si es necesario.

\subsection{UTENSILIOS EN LOS QUE SE PREPARABA LA COMIDA}

\subsubsection{Ollas de cocción}

Los habitantes del Sáhara Occidental cocinaban tradicionalmente en ollas, denominadas mrâŷan — sing. märŷän — (Baya 2007a: 29), que se fabricaban con un tipo de hierro fácil de romper y pesado como el plomo, llamado təngərdä (Baya 2007a: 120), y de otros metales como el cobre o el aluminio. También se confeccionaban

\footnotetext{
${ }^{14}$ Esta práctica se enmarca también dentro de lo que podemos denominar arreglos provisionales o "apaños" del desierto.

${ }^{15}$ En vez de piedras de et-təmmiš, que son fáciles de romperse con el fuego, o piedras de țavșä, ya que cuando se calientan y se mojan o se prolonga su uso, colocando las ollas encima de ellas, acaban rompiéndose también. Sin embargo, las piedras șuniyāt, que quiere decir zagrāt, ukidāt o mān'āt (duras, compactas, resistentes), son difíciles de romperse y no son demasiado mšanzrāt, ni tampoco mkärkbāt (redondas), ya que estas facilitan el deslizamiento de la olla y se resbalan ellas también si la tierra es dura.
} 
marmitas de barro ( $g d \bar{u} r t-t \underline{i} n$ ) para usos más generales y extendidos. Igualmente se preparaba la comida en ollas de aluminio (ștāli r-rīšs, sing. șäțä), de fabricación casera. Otras denominaciones de ollas de cocción son: șațla, pl. ștāli (Aguilera 2006: 45) y gamīla, pl. gwāməl, que se fabrican de aluminio y de hierro.

\subsubsection{Asado sobre piedras, sobre tierra, en hoyos y fosos (pozos)}

En lo que se refiere al asado -eš-šey/šwä (Aguilera 2006: 7), se preparaba sobre piedras. Se ponían estas a calentar y se colocaba la carne encima para asarla. También se asaba sobre la tierra. Para ello se excavaba un hoyo, se colocaba leña en él, se encendía el fuego, se dejaba calentar bien, se retiraba la brasa, se enterraba la carne en el suelo y se encendía el fuego de nuevo sobre la misma tierra, pero no tan intenso como en la primera. Igualmente se asaba la carne dentro de fosos. El modo de preparación de estos fosos es el siguiente: se excava un pozo — hassī- (Ould Mohamed Baba 1996: 189, 208) de una altura equiparable a la del tamaño de una skițä (animal sacrificado - generalmente una cabra, cordero u oveja-), se llena de leña, se prende fuego a la leña y se espera a que el fuego esté bien encendido; después se coge un palo y se ata a él la skiṭä (una o más de una si las hay) colgándola por sus patas traseras (lognādīz l-wärrāniyin); entonces y así preparada, se descuelga la skiṭä en el pozo y se tapa su boca con una bandeja grande u otro objeto similar para, más tarde, cubrirla de arena hasta taparla por completo. Tras poco tiempo de haber introducido la carne, esta estará hecha.

\subsection{Material más saludable para cocinar}

Este apartado no deja de estar relacionado con el anterior, pero debe matizarse algo más incorporando nuevos elementos y datos útiles. Se distinguen, generalmente, dos formas de preparar la carne en el Sáhara Occidental: la et-bījä y el eš-šey.

\section{Et-bījä}

Təngərdä (un tipo de hierro semejante al plomo, pero más quebradizo) es el material más salubre para cocinar y la olla de təngərdä es la más apreciada. Este apreciado tipo de hierro (Marín 1999: 167) ${ }^{16}$ tiende a romperse cuando se calienta y se rocía con agua, sobre todo si se utiliza como säjjānä ${ }^{17}$. A diferencia de la təngərdä, el plomo ( $\bar{a}$

\footnotetext{
${ }^{16}$ Manuela Marín (1999) señala (en un estudio sobre los dos únicos recetarios andalusíes conocidos hasta la fecha: Faḍalāt al-jiwān fi țayyibāt at-ța'ām wal-alwān y Kitāb al-Ṭabīj, ambos recogidos en la bibliografía de este artículo) que «los recipientes de hierro son los que se recomiendan en primer lugar, siempre y cuando se cuiden con atención para evitar la aparición de herrumbre, para lo que es bueno tratarlos con miel" y añade: "tomando en cuenta estas precauciones, los recipientes de hierro son incluso beneficiosos para la salud, ya que fortifican los miembros del cuerpo". Esta percepción sigue vigente y arraigada hoy en día en muchos rincones del Sáhara, especialmente, entre los más ancianos a los que tuvimos la oportunidad de consultar para la realización de nuestro trabajo de campo.

${ }^{17}$ Calentadora. Tabla de hierro u otro metal parecido, de forma rectangular o circular, cuya medida alcanza, aproximadamente, los cincuenta centímetros.
} 
ldūn) no se rompe, pero sí se tuerce fácilmente. La marmita de barro (gədrä —pl. gdū r- (Ould Mohamed Baba 2007: 196), conocida por el nombre de "puchero" (Lerchundi 1892: 651), constituye, junto con la anterior, las de características más salubres para preparar la carne cocida $(t$-tbījä). Les siguen otras ollas como las de aluminio (sätlat $r$ rīs), pero las más apreciadas son las dos anteriormente mencionadas porque se cocina en ellas de un modo más natural.

\section{$E \check{S}-\check{s} e y$}

La mejor carne asada (eš-šey) para los beduinos es aquella que se prepara a la brasa y está poco hecha, es decir, que conserva un poco de sangre, que hace la carne más sabrosa. Mientras que la carne muy hecha, en algunos casos, casi quemada, pierde su sabor y es perjudicial para el estómago. En las preferencias de los beduinos, a la carne asada a la brasa le sigue aquella asada al rescoldo (ärukāll ${ }^{18}$, luego la hecha sobre piedras, después la que se ablanda por tueste o torrefacción ( $\bar{a} f-f \bar{a} r$ ), como el asado según la técnica del pozo excavado.

La carne que se vaya a degustar, tanto la cocida como la asada, adquiere un sabor especial si se acompaña con $e d-d h \partial n^{19}$, ya que este hace que la carne resulte deliciosa y tenga propiedades más sanas. Entre las comidas locales hay una especial y muy apreciada que consiste en abrir el apetito con dátiles a los que sigue la carne. Luego se ofrece pan troceado sobre el que se echa la salsa de la carne cocida con anterioridad y un poco de ed-dhən. Este plato constituye uno de los manjares más apreciados por los beduinos saharauis.

\subsection{INSTRUMENTOS Y VASIJAS PARA EL TRATAMIENTO DE LA LECHE}

\subsubsection{La leche y su importancia en la vida de los nómadas}

Es muy conveniente hablar de la importancia de la leche en la vida de los $b \hat{\imath}$ "ân, en particular, y los árabes, en general, antes de empezar a desarrollar el capítulo relativo a las vasijas en que se servía y se sirve aún en nuestros días.

Los vínculos que unen a los saharauis con la tradición y el consumo de la leche son muy fuertes y se remontan a tiempos muy lejanos, algo visible también en la ceremonia del té. Entre los saharauis, la leche se consume en un ambiente al que las costumbres de la región le confieren cierta singularidad, que puede llegar a considerarse sui generis en lo que se refiere a las buenas maneras en el comer y el beber (Baya 2007a: 80). Esta singularidad se manifiesta en la forma de preparación y la manera de consumo y de ordenar sus utensilios, además del contexto cultural que la rodea, con sus sólidas influencias en la consolidación de los vínculos de convivencia social.

\footnotetext{
${ }^{18}$ Brasa menuda resguardada por la ceniza o rescoldo, y también significa "arena caliente" (Baya 2007a: 89). Este término puede ser fácilmente de origen bereber, ya que también existe en el sustrato de esta lengua el vocablo tarukālet.

${ }^{19}$ Grasa animal que se conserva en dos tipos de pellejos de piel denominados 'əkkä y agərt (Baya 2007a: 18, 19). El primero consiste en un pellejo de piel que se utiliza para conservar la mantequilla y otras grasas animales y es de uso muy extendido. El segundo es un recipiente de cuero para guardar el dhən propiamente dicho y también dátiles.
} 
La leche que se ofrece a los huéspedes junto con los dátiles como señal de caluroso recibimiento y excelente forma de conducta social se considera una de las tradiciones más antiguas del mundo árabo-islámico y constituye un tema rico y omnipresente en la literatura árabe, donde se la relaciona directamente con al-Kafä' (pureza, rectitud y sinceridad) y $a l$-'ața ' (generosidad y entrega). No es de extrañar, pues, que la importancia de la leche se mantenga hoy presente y viva en el Sáhara Occidental, región que se caracterizó antaño por la escasez de agua y el recurso de sus habitantes nómadas a la cría de camellos y reses que constituyen la fuente de producción de la leche.

\subsubsection{El odre. Preparación de la leche y obtención de la mantequilla}

Otro apartado no menos importante es el de la preparación de la leche en el odre y la obtención de la mantequilla (Benchekroun 1981: 150). La mantequilla se obtiene a partir de la leche que se bate en el odre después de cuajarse. La leche ordeñada, se pone en una colodra de tamaño medio llamada el-märwäb (vasija de cuajar leche), hecha de material diverso y con nombres locales variados, según la región, la capacidad, el tipo de madera, etc. Debajo de ella se coloca un poco de arena templada, se tapa y se pone en un lugar apartado o alejado de la vista de la gente hasta que la leche esté totalmente cuajada ${ }^{20}$. A continuación se vierte la leche en el odre eš-šəkwä (Ould Mohamed Baba 2007: 198) y se infla este. La mujer, que suele ser - casi siempre- la encargada de esta labor, coloca una tela fina entre su boca y el orificio del odre y lo hincha, luego lo ata y lo cuelga en una especie de trípode ( həommārä), tras lo cual empieza a moverlo y agitarlo hacia atrás y hacia delante hasta que la mantequilla se haya formado completamente.

\subsubsection{Ordeño de cabras y camellas (et-təḥlāb)}

Las cabras (ləg்øəm) y las vacas (ləbgär) se ordeñan en un recipiente (gdäb) parecido a un almirez llamado et-tādit, con fondo circular y una muesca o entalladura ( $h \ddot{a} z z \ddot{a}$ ) en la parte de abajo y largo por arriba, aunque el tādit posee un asidero (jörb) en el extremo por donde se introducen los dedos. Si es de tamaño grande, debe poseer dos asas para poder moverlo. A la hora de ordeñar se colocan los dedos en el asa izquierda y se ordeña con la mano derecha. El fondo del tādit es diferente al del almirez —mebrāz- (Aguilera 2006: 41). Guillermo Rosselló (1994) recoge que el autor de Kitāb al-Tabīj señala que «en la cocina debe de utilizarse el almirez de madera o piedra, pues el metálico puede deteriorarse según qué tipo de

\footnotetext{
${ }^{20}$ La idea de alejarla de la vista de los "forasteros" se enmarca dentro de las creencias y la superstición propias de muchos nómadas, ya que piensan que, si la obtención y extracción de la mantequilla se hace ante la presencia de personas ajenas a la morada, estos pueden influir negativamente en su calidad y de ahí que relacionen también esta eventualidad con el mal de ojo. Una actitud parecida se puede observar en los nómadas de las regiones argelinas de Aumale y Sidi-Aïsa (M‘Hamsadji 1955: 22).
} 
alimentos ${ }^{21}$. Cabe destacar también que el fondo del almirez, en general, es más grueso, contiene restos de madera que le sirven a la hora de majar, ya que este tipo de mortero se emplea exclusivamente y entre los saharauis, para moler (ig̈äyyäz) la cebada u otros granos. También, a veces, se utiliza para la cebada tostada (logliyyä), cuando se prepara para ser tomada como remedio para alguna enfermedad. En cambio, el fondo del tādit está totalmente liso, sin restos de madera y es muy ligero. Se fabrica, tradicionalmente, de una madera liviana, llamada también et-tādit o et-tādd $\bar{u}$ $t$ (Acacia gummifera Willd.). Se ordeña con él tanto el ganado caprino como el vacuno.

Para el ordeño de camellas se utiliza el ädərs. Cuando llega el-ätmä-el lapso de tiempo que coincide con las primeras horas de la noche- y los beduinos se disponen a ordeñar las camellas a su vuelta al establo —ez-rībä- (Baya 2007a: 126), se prepara el ädors, se lava bien, las dos personas que vayan a ordeñar la camella proceden a detenerla y a esperar a que las ubres del animal estén listas para ser ordeñada, es decir, (äz-zör). En ese momento, uno de ellos llama al otro para que se acerque con el ädors, ambos se meten debajo de la camella, colocan sus cabezas justo debajo del vientre de la bestia y empieza uno a ordeñar con las dos manos, mientras el otro sostiene el recipiente. A veces, uno de ellos coge el ädors con una sola mano y con la otra ordeña una de las dos ubres libres ${ }^{22}$. Cuando ha obtenido una cierta cantidad de leche, el que está ordeñando golpea el ädors con dos de sus dedos (índice-corazón) en señal de que ya ha terminado de ordeñar y avisa al otro para que se aleje y vierta la leche en otro recipiente más grande llamado täzuwä y prosiga la tarea o bien la dé por concluida. Si la leche lleva incorporada mucha espuma ( $r$-rəg்äa) y se quiere degustarla retirándola, se emplea el término ŷälwäy recipiente que contiene la leche. Los beduinos recomiendan que antes de ordeñar la vaca o la cabra se ponga el tādit o el ädors al fuego a calentar; una vez calentado, se retira del fuego y se traslada al lugar donde se va a llevar a cabo el ordeño. La ventaja de calentar el recipiente es que mantiene la leche caliente o, por lo menos, retrasa su enfriamiento y la hace más espumosa. Así, se ordeña tanto con ädərs como con el tāait ${ }^{23}$.

\subsection{INSTRUMENTOS PARA EL TRATAMIENTO DEL GRANO}

Para el tratamiento de los granos se utilizan, generalmente, dos tipos de instrumentos básicos, que son el molino de mano (er-rhäa) y el almirez —el-məhrāz(Ould Mohamed Baba 1996: 160), además de otros utensilios complementarios tales como el lemdäggä (pl. mdäggāt), mango inseparable del mortero que se usa, entre otras cosas, para quitarle la cáscara a la cebada después de tostada o seca; el ġarbāl

\footnotetext{
${ }^{21}$ Huici Miranda $(1965,2005)$. Traducción española, p. 90. Texto árabe p. 84. Las normas se reseñan en un capítulo especial titulado: "De los utensilios que necesita usar el que se ocupa del oficio de cocinar y de la farmacia".

${ }^{22} \mathrm{La}$ camella posee cuatro glándulas mamarias; las dos ubres delanteras se llaman ləmgādəm, las traseras se denominan ləmmājor.

${ }^{23}$ Como ejemplo ilustrativo se ha escogido la técnica más usada para ordeñar la camella, por ser la más complicada y completa en comparación con la de la cabra o la de la oveja.
} 
—pl. grabīl_ (Ould Mohamed Baba 2007: 198; Aguilera 2006: 13-14), tamiz o cedazo de tipo común europeo en que se cierne la harina (M'Hamsadji 1955: 13); el tbäg — pl. țöbga - (Aguilera 2006: 13), cobertera o bandeja de esparto o de junco, de uso parecido a la gäṣ̆ä. Esta bandeja se usa también para servir, entre otros productos, la cebada tostada, dátiles, gärtä (cacahuetes), etc. (Brunot 1921: 124). Esta fuente corresponde al "étimo del tabaque castellano o tabac catalán, muy frecuente en la documentación medieval cristiana y con una amplia pervivencia en los ajuares cerámicos medievales también cristianos. En los glosarios árabes, especialmente el Anónimo de Leiden y El Vocabulista, observamos una gran variedad en cuanto a los significados de thäg. Es una pieza de función múltiple como servicio de mesa, tapadera, posiblemente para ahornar el pan" (Rosselló 1994: 61-62). La gäs ‘ä (pl. gșä), bandeja grande de madera donde se sirven la carne y las papillas, es el recipiente más usado por los beduinos, tanto para las elaboraciones culinarias como para su consumo ${ }^{24}$. Existe también el țabsīl — pl. țbāsīl- (Aguilera 2006: 49), fuente más común que se usa para comer, fabricado en las últimas décadas en metales de diferentes tamaños y colores y recogido desde antaño por muchos autores (Lerchundi 1892: 619). Y también está el kaskās, cuscusera, vasija de esparto, generalmente en forma de embudo, que se coloca encima de la olla para hacer el alcuzcuz. El kaskā $s$ posee un borde más ancho y se utiliza también en la presentación de alimentos (Bel y Ricard 1913: 105).

Estos utensilios son imprescindibles en la jaima de cualquier beduino ya que sin ellos es casi imposible sobrevivir, pues el alimento tradicional, es decir, la cebada, necesita ser tratada y preparada por medio de estos instrumentos (Baya 2007b: 3036) ${ }^{25}$. En su mayoría, estos utensilios se fabrican de la madera obtenida de arbustos

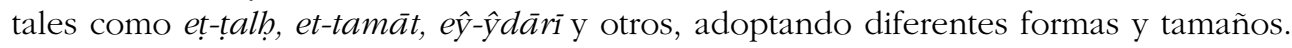
En cuanto a los cedazos, los hay de madera y metal, si bien antiguamente se confeccionaban, sobre todo, con madera y piel. Las coberteras y las grandes bandejas se fabrican también de los mismos arbustos, pero se suelen importar, generalmente, de Mauritania.

\section{UTENSILIOS}

Sobre este material de cocina ya hemos hecho alusión directa o indirecta en diferentes apartados. Ahora vamos a profundizar algo más y procederemos a describirlos de manera más completa, aunque breve, a fin de ofrecer una visión general acerca de su uso y aprovechamientos.

\footnotetext{
${ }^{24}$ M'Hamsadji, en su artículo antes citado, ofrece diferentes nombres de gäs ‘ä según el tamaño, la región o el alimento que contiene y así cita las siguientes denominaciones: $\hat{y} e v n a$, neșṣāviyya, bagșiyya, șabuva y durrāŷy.

25 Esta monografía (dedicada casi en exclusivo a la producción, preparación y consumo de los alimentos tradicionales en el Sáhara Occidental) incluye un apartado sobre la cebada, el molino de mano y las variedades culinarias que se elaboran a base de cebada y otros cereales.
} 


\subsection{RECIPIENTES PARA BEBER}

La leche ordeñada se vierte sobre un embudo de madera llamado lmöhgən -pl. mhägən (Aguilera 2006: 21; Ould Mohamed Baba 1996: 162). Esta leche se conserva en grandes cuencos de madera denominados tizuwāten (pl. de tazuwä), capaces de almacenar hasta veinticinco litros de leche de camella, ordeñados en el momento en que los animales regresan de haber pastado durante el día. Los tizuwāten tienen forma semiesférica. Los más grandes poseen cuatro asas y dos los medianos. También son utilizados para recoger la leche de cabra y de oveja. Entre los recipientes que utilizan los beduinos saharauis para beber destacamos los siguientes: gädḥä o gdäḥ (pl. gädḥāt o gədḥān ${ }^{26}:$ cuenco de forma semiesférica sin asas y de diferentes tamaños, con una capacidad aproximada de dos a seis litros, en donde se bebe, generalmente, la leche.

a) Ädərs - pl. idərsān- (Baya 2007a: 19), del que ya se ha hablado antes. Se trata de un recipiente muy ligero que se utiliza, por lo general, para el ordeño, aunque ciertas familias lo aprovechan también para beber. Habitualmente no se les sirve a los huéspedes la leche en él, pues para este menester se utiliza la gädhä. La capacidad del ädərs oscila entre cinco y ocho litros. Este recipiente presenta una pestaña cerca del borde para que no resbale al cogerlo. La pestaña tiene dos agujeros para la cuerda que ha de sostenerlo durante el transporte.

b) Äsəllāy: cuando se ha de servir la leche, se emplea el cuenco llamado asəllāy - pl. isəlləyən - (Baya 2007a: 20), que es de forma semiesférica, con una sola asa y una capacidad de siete a nueve litros aproximadamente. Su tamaño está un poco por encima del de una täzuwä (utilizada para recoger la leche de camella o de cabra) y el de la gädḥä propiamente dicha, con la desventaja de que el asəllāy hay que sujetarlo con las dos manos, mientras que la gädhä se puede manejar con una sola mano (Ould Mohamed Baba 1996: 180-183).

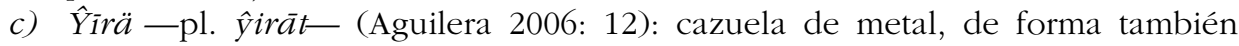
semiesférica con distintos tamaños y colores, y de uso más reciente, que se utiliza para servir la leche u otro líquido.

d) $A \dot{g} a ̈ r r a \bar{f}$ (pl. àgrāarîf): cazo común con asa de material metálico o de aluminio que se usa para beber. Algunos autores lo llaman "jarra" (Lerchundi 1892: 449).

e) La tasüfra, piel de cabra pequeña en que se suele transportar la leche durante los desplazamientos por el desierto sin que, en general, llegue a estropearse. Tiene cabida para contener de seis a siete litros.

De todos estos recipientes reseñados, solamente se usan con frecuencia, hoy en día, la gädḅä, la ŷîä y el ag்ärräf, llamado también $k a ̄ r r$, que es un nombre de origen mauritano-senegalés.

Otros recipientes importantes para los beduinos son:

1) el dälw: recipiente elaborado, generalmente, con piel curtida de borrego que sirve para extraer agua de los pozos. Pl. dli. Se trata de un término clásico presente en todos los países de habla árabe (M'Hamsadji 1955: 9-10).

2) $\check{G} \ddot{r} r \ddot{a}:$ dälw grande, confeccionado de piel de camella. Pl. gräf.

${ }^{26}$ Acerca del material y tipos de este recipiente, véanse Beaussier (1887: 258), Dozy (1881, II: 312) y Alcalá (1883: 280). 
3) Hawz (Aguilera 2006: 5): abrevadero hecho, por lo general, de piel de camella en el que se echa agua extraída de los pozos mediante un recipiente. Pl. aḥwāz. Estos recipientes están empezando a desaparecer, substituidos por otros de material metálico y vítreo.

\subsection{RECIPIENTES PARA COMER}

En relación con los recipientes o fuentes que se utilizaban tradicionalmente para comer, se puede decir que eran muy escasos y los pocos que había se usaban para servir los diferentes platos que se elaboraban. Algunos de ellos ya han sido mencionados, de manera indirecta, en las páginas anteriores.

Para servir la carne asada, los beduinos saharauis empleaban la cobertera tbäg. Variedades culinarias tales como el äiš (gachas), kəskəs (alcuzcuz), lhäm (carne), etc. (Baya 2007b), se ofrecían en una gäṣä (bandeja grande). Otros platos elaborados a base de cereal tales como bulg̀mān, ez-zämmit, ārkūk, podían ser presentados en fuentes más comunes llamadas ṭbāsīl (sing. țäbsīl) —ya mencionadas antes-, fabricadas en las últimas décadas de metales de diferentes tamaños y colores.

Otro material omnipresente en la morada de cualquier árabe del Magreb, en especial los bizān, es el relacionado con la ceremonia del té. En 1882, España introdujo el té en el Sáhara a través de la ciudad de Dajla (antigua Villa Cisneros), aunque la variedad que importó no era de buena calidad y pertenecía al tipo llamado nigru (té negro). Años más tarde lo distribuyó también por la zona de Tarfaya (antiguo Cabo Juby), a partir de estas fechas, el té empezó a extenderse por el territorio del Sáhara procedente de Marruecos, concretamente de la ciudad costera de Essaouira. El té habría llegado a esta ciudad marroquí entre 1810 y 1815 gracias a unos comerciantes ingleses que transportaban té verde en un barco que atracó en dicho puerto debido a una avería, ya que su destino no era esa $\operatorname{ciudad}^{27}$. De ahí procede el nombre de eš-šây eș-șwayrī (té de Essaouira), que se mantiene hasta hoy día en alusión a la mencionada villa y al té verde procedente de ella. Según Leriche ${ }^{28}$, el té llegó a Mauritania y al Sáhara Occidental a través de comerciantes de la tribu de Awlād Bəsba‘ o Abu esSibā', quienes lo importaron desde Francia a la zona en 1810, aproximadamente. Su llegada a la región originó fuertes polémicas y topó con numerosas y duras críticas, especialmente por parte de grupos religiosos, algunos ulemas y alfaquíes que temieron que contuviera algún tipo de narcótico (Baya 2007b: 85).

\footnotetext{
${ }^{27}$ En sus Estudios Saharianos, y en relación a la actividad comercial en la región, Caro Baroja (1955) alude — en nota a pie de página - a una obra titulada "Naufrage du brigantin américain de Commerce, perdu sur la Côte Occidentale d'Afrique, au mois d'août 1815: accompagné de la description de Tombouctou et de la grande ville de Wasanah inconnu jusqu'à ce jour: publié par M. James Riley, ancien capitaine et surecharge du dit brigantin. Traduit de l'anglais par M. Peltier, II (Paris, 1818)", pp. 76-77. Esta obra, que consta de dos volúmenes, es poco informativa en general y hay que advertir que el texto referente a la tribu de Ulād Bəsba' se halla ya en el "Extrait de la description de l'Empire de Maroc, par James Grey Jackson, écuyer publiée à Londres en 1814", pp. 65-111 del volumen citado.

${ }^{28}$ En su trabajo Leriche (1953) ofrece información valiosa acerca de la llegada del té a Marruecos y a la región del Sáhara.
} 
Los utensilios que intervienen en la ceremonia del té son básicamente los siguientes:

a) el-kisān ${ }^{29}$ (vasos).

b) äbarrād täsəmmimət (tetera para té). Este tipo de tetera es distinto de la llamada ābrīq (pl. ibərqân) $)^{30}$, puesto que esta última se reservaba, tradicionalmente y casi siempre, a los beduinos que se ocupaban de las labores de pastoreo o que acompañaban a los camellos lejos del frīg (campamento de jaimas) y pasaban largas jornadas con el ganado (em'azbin), así como para todos aquellos nómadas con poco tiempo para el té y las largas reuniones. La ābrìg es un tetera más consistente que la täsəmmimət y resiste mejor si se coloca directamente sobre la brasa, siendo utilizada en las continuas ceremonias de té preparadas a la intemperie y en condiciones poco favorables.

c) t-țäblä es la bandeja donde se colocan los vasos y la tetera.

d) el-mägrä̂̀ o tetera para hervir el agua.

e) el-mäŷmär es un brasero de tres patas (Alcalá 1883: 119).

f) ləfrənnä (Ould Mohamed Baba 1996: 199), que es un brasero sin patas ${ }^{31}$.

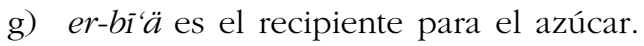

b) ez-zambìl, que es un envase para guardar la hierba del té.

i) Imäkäsrä es una especie de mazo para trocear el azúcar de pilón.

\subsection{Cucharones, Cucharas, navajas y CUCHILlos}

En este capítulo poco se puede reseñar en cuanto al material utilizado por los beduinos saharauis y que pueda corresponder a lo que hoy entendemos por cucharas o cuchillos. Sin embargo, se pueden destacar unos rústicos cucharones de madera, denominados mrāgìi (sing, mərg்āyä), que se usaban, generalmente, para servir variedades culinarias como la ed-dšišä (sémola de cebada, triturada con harina de este mismo cereal) o alcuzcuz. Otro utensilio multiuso y omnipresente en los hogares beduinos tradicionales es el llamado mus 'âd (palo de madera con que se remueven hasta espesar variedades culinarias como el'äiš, bulġmān, etc.). También se fabricaban cuchillos y navajas. De ello se encargaban y se encargan profesionales artesanos ( m’älmīn, m’älmāt, sing. m‘älläm, m’älmä). Entre los cuchillos estaba el el-mūs pl. ämmās (Ould Mohamed Baba 1996: 200), por lo general de hierro, formado por una hoja de un solo corte y un mango ( gäbzä). Se confeccionaba también una funda de piel para guardarlo. Asimismo, se fabricaba un cuchillo idéntico, pero con un mungās (pinza para sacar espinas) colocado en su mango y unas artesanas navajas (skākinn, sing. səkkin), también llamadas ləjnāŷìr , cuyo mango era de madera y su funda de plata, y que tenían doble asa en el mango y en el asa.

\footnotetext{
${ }^{29}$ Brunot (1921: 111-140) expone en la página 136 distintos tipos de vasos en función del material del que están confeccionados. Así cita $k \bar{a} s$ bdī' (loza), taous (porcelana fina), vejjār (terracota: la arcilla modelada y endurecida al horno), $\hat{y} a \hat{y}$ (cristal).

${ }^{30}$ Es de suma importancia la descripción que ofrece Monod (1955: 71-72) acerca de las distintas formas y tamaños de las teteras.

${ }^{31}$ En el desierto, generalmente, se coloca la brasa en una höorä (hoyo) y se pone la tetera encima de dicha brasa.
} 


\section{USO Y APROVECHAMIENTO DE LOS ARBUSTOS}

La inmensa mayoría de los recipientes de madera se fabricaban a partir de las cuatro siguientes especies leñosas más representativas de la zona: eț-țalh, et-tamāt, ề$\hat{y} d \bar{a} r \bar{y}$ y teyššat.

Et-țalh (Acacia tortilis - subsp. raddiana [Savi] Brenan). Árbol de dos a diez metros de altura, de flores blanquecinas y con vainas en forma de espiral. La țalha está presente en la cultura tradicional saharaui en dichos, cuentos y canciones. En una canción tradicional, el estribillo dice "lurag talh, lurag tamāt" (hojas de acacia), en referencia a las hojas de estas dos especies de acacia (Volpato 2008: 22). Es el árbol de más porte de entre los que pueblan el Sáhara Occidental. Es sumamente útil y se aprovecha su sombra, su leña y su apreciada madera con la que se fabrican palos especiales y sillas de montar, además de piezas del ajuar doméstico como cucharas, cuencos, soportes para colgar los odres de agua y de leche, etc. (Barrera et al. 2007: 92-93). Se considera como el gran recurso del nómada (Guinea 1947: 57).

$E \hat{y}-\hat{y} d \bar{a} r \bar{i}$ (Rhus tripartita [Ucria] Grande $=R h$. Oxycantha auca.). Se trata de un arbusto muy ramoso con espinas en las extremidades de las ramas, flores blancas y frutos rojos negros en su madurez (Volpato 2008: 93). Es un árbol omnipresente en la zona norte y próxima a la costa del Sáhara Occidental. Constituye el núcleo arbóreo más importante de las graras (formaciones leñosas y conjuntos arbóreos formados por arbustos y maleza) y se extiende hacia el sur hasta alcanzar el Trópico de Cáncer (Guinea 1947: 59). Sus hojas sirven como sucedáneo para preparar el té; su corteza y hojas se utilizan para curtir pieles, especialmente los recipientes de piel de cabra para transportar agua (løgrəb, sing. gərbä). De su madera se fabrican numerosos objetos de uso cotidiano, muchos de ellos ya mencionados en este trabajo: embudos, cuencos, etc. (Barrera et al. 2007: 32). Los beduinos comen crudos sus frutos ya que son dulces y, para que se conserven frescos largo tiempo, los mantienen dentro de los ya indicados ləgrəb, sing. gərbä, procedimiento que da muy buenos resultados en el ambiente seco del desierto (Guinea 1947: 60).

Et-tamāt (Acacia ebrenbergiana Hayne $=$ A. flava [Forssk.] Schweinf. $)^{32}$. Es un arbusto de menos de cuatro metros de altura, de flores amarillas y vainas largas y finas (Volpato 2008: 16). Este árbol es semejante a eț-talh, tanto en las espinas como en la madera, aunque el sabor de sus hojas es más amargo que el de et-țalḥ y constituyen mejor curtiente que las cortezas de $e \hat{y}-\hat{y} d \bar{a} r \bar{i}$ y del propio țalh, ya que la suya (su corteza) es más amarga y más espesa. Con su madera se elaboran numerosos utensilios domésticos (recipientes para comer y beber) y otros instrumentos útiles para la ganadería, el transporte y la agricultura (Barrera et al. 2007: 95). Su resina también es muy amarga y no sirve de alimento complementario.

Teyššaț (Balanites aegyptiaca [L.] Delile). Es un árbol o arbusto que puede alcanzar los siete u ocho metros de altura, cuyos frutos son constituidos por una drupa carnosa de 1-2 centímetros (Volpato 2008: 44). Su madera y sus palos son muy apreciados por los nómadas y sus espinos son de alta calidad; su madera se utiliza de una manera muy

\footnotetext{
${ }^{32}$ Durante mucho tiempo se ha identificado el tamāt con Acacia seyal Delile, que no es planta del Sáhara Occidental. Uno de los rasgos que mejor distinguen a la A. ebrenbergiana (tamāt) es la corteza marrón rojiza que se desprende en tiras o láminas escamosas (Barrera et al. 2007: 96).
} 
extensa en la construcción de monturas de camello (rạḥla) y tablillas para las escritura —lawh- (Guinea 1947: 133). También es aprovechable su leña, su sombra durante las elevadas temperaturas diurnas y el calor que desprende en las noches gélidas. Su madera es más dura y resistente que otros tipos de madera y de ella se hacen numerosos instrumentos y utensilios de cocina — bandejas, cuencos, cucharones, etc.- (Barrera et al. 2007: 102).

De las raíces leñosas de estos árboles se fabrican las mencionadas colodras y los citados cuencos y cazos semiesféricos y esféricos de diverso tamaño, además de los mazos de almirez.

A modo de recapitulación, podemos añadir que todo lo que se cuece en el märŷän, la gədrä y eș-șätlä (Lafuente 1996: 176) se sirve con el cucharón llamado mərg்āyä (pl. mrāgìi) o en la gäṣä (sing. gṣä), que están fabricados con la madera extraída de estos árboles. De los mismos arbustos se hacen los gədhānn (sing. gädhä, colodra). Si la rama es gruesa, se confeccionan con ella los tizuwön (sing. täzuwä, cuenco) o los isillāyən (sing. äsəllāy, recipiente más pequeño que la täzuwä). De la misma madera se confeccionan también el lomṣäb (más pequeño que el äsəllāy), la colodra grande ( gädhä kbīrä), la mediana, la que la sigue en tamaño y también la pequeña conocida con el diminutivo de gdeyhä. También de la misma madera se fabricaba y se fabrica el cazo semiesférico išigìm - pl. āšwagìm (Aguilera 2006: 12), que se utiliza para el trasvase de la leche entre diferentes recipientes. Estas colodras o gədḥān (es decir, de la gädḥä grande hasta el tamaño más reducido) sirven para ordeñar los camellos, beber en ellas o también usarlas para comer. Pero hay colodras — como ya se ha visto antes - reservadas para cada uso. Por ejemplo, el ädərs (diminutivo ädräyəs), que puede ser una gädḥä grande, mediana o pequeña, presenta una pestaña ('orwä) cerca del borde para que no resbale al cogerla y se usa especialmente para ordeñar camellas.

\section{A MODO DE CONCLUSIÓN}

El objetivo de este trabajo apunta, básicamente, a la investigación de dos cuestiones generales: la primera se refiere al material culinario utilizado tradicionalmente por los habitantes de la región del Sáhara Occidental, y la segunda pretende el registro del bagaje lingüístico-semántico vinculado a dicho material. Dentro de las limitaciones lógicas inherentes a la documentación escrita relacionada con la alimentación y la cocina tradicional en las sociedades beduinas de África Occidental, en concreto del Sáhara Occidental y Mauritania, que es escasa - por no decir inexistente-, se ha intentado rescatar una parte importante del legado cultural culinario saharaui —basándonos esencialmente en fuentes orales y destacando de manera implícita los rasgos distintivos de la identidad de los habitantes autóctonos de la zona- y resaltar la terminología específica conservada en el dialecto árabe hassāniya.

Los apartados desarrollados muestran, de alguna manera, la variedad léxica característica de dicho dialecto, que, a nuestro juicio, requiere un estudio lingüístico taxonómico más profundo a fin de poder ordenarla por campos semánticos y realizar, si es oportuno, un análisis etimológico que nos acerque más al origen preciso de dichos vocablos. Igualmente, quizás se pueda constatar la falta de uniformidad en cuanto a la profundi- 
dad con la que se ha tratado cada capítulo, fruto, como se ha señalado, de la escasez de la documentación afín al tema que nos ocupa. No obstante, se ha podido dotar al estudio de cierta homogeneidad a través de las continuas referencias cruzadas que se han realizado entre los distintos elementos analizados, y la interrelación existente entre los distintos apartados contribuye a mantener vivo el hilo conductor que une las distintas partes.

La clasificación de recipientes para comer, al igual que algunos de los que se utilizan para beber, está ampliamente aceptada y consensuada por los beduinos saharauis, aunque, eso sí, pueden darse mínimas diferencias en su denominación y asignación de una región a otra, en función de la "disponibilidad" o no de los recursos naturales para su obtención y elaboración. Además, si se sabe de antemano que la situación antaño del beduino fue muy particular y las posibilidades de poder alternar el uso de dichos utensilios se da "en muy determinados casos", esta clasificación no deja de cobrar fuerza, dadas las necesidades particulares de dicha sociedad.

\section{BIBLIOGRAFÍA CITADA}

Aguadé Bofill, J. 2008. "Árabe marroquí (Casablanca)", en Estudios Árabes e Islámicos. Estudios de Dialectología Árabe 1: 281-310. Zaragoza: Instituto de Estudios Islámicos y del Oriente Próximo.

Aguilera Pleguezuelo, J. 2006: Diccionario español-árabe hasanía. Málaga: Cedma. Alcalá, P. 1883. Petri hispani de lengua arabica libri duo. Gottinga: Lagarde.

Barrera Martínez, I. et al. 2007. Sahara Occidental: plantas y usos. Madrid: Universidad Complutense de Madrid.

Baya Essayahi, M. L. 2002. El Sahara Occidental: alimentación y cocina tradicional. Aspectos culturales, lingüísticos y etnobotánicos. Tesis doctoral. Universidad de Granada.

Baya Essayahi, M. L. 2004. "Sources for the study of food history in Western Sahara". Food E History II (1): 275-281.

Baya Essayahi, M. L. 2007a. Breve gramática y diccionario temático bilingüe árabe hassāniya- español. Granada: Comares.

Baya Essayahi, M. L. 2007b. Traducción y estudio de fuentes orales sobre la producción, preparación y consumo de los alimentos tradicionales en el Sabara Occidental. Aspectos culturales, lingüísticos y traductológicos. Sevilla: Universidad de Sevilla.

Beaussier, V. 1887. Dictionnaire pratique arabe-français. Alger: Librairie Adolphe Jourdan.

Bel, A. y Ricard, P. 1913. Le travail de la laine à Tlemcen. Alger: A. Jourdan.

Benchekroun, M. 1981. La cuisine andalou-marocaine au XIIIe siècle d'après un manuscrit rare: Fạ̣alāt al-jiwān fịtayyibāt aț-ța'ām wa-l-alwān, d'Ibn Razīn alTuŷīìi. Rabat: Maṭba'at al-Risāla.

Brunot, L. 1920. Notes lexicologiques sur le vocabulaire maritime de Rabat et Salé. París: Ernest Leroux.

Brunot, L. 1921. "Noms des récipients á Rabat". Hespéris I: 111-140.

Caro Baroja, J. 1955. Estudios saharianos. Madrid: CSIC. 
Colin, G. S. 1930. "Mauritanica”. Hespéris XI: 31-32; 133-143..

Dozy, R. 1881. Supplément aux dictionnaires arabes, II vol. Leide: E. J. Brill.

Guinea, E. 1947. España y el Desierto. Madrid: Instituto de Estudios Africanos.

Hamdātī, Ch.M. 1998. Qabā'il al-Sahrā̄' al-Magribiyya. Rabat: Al-Maṭa'a al-Malakiya. Huici Miranda, A. 1965. Kitāb al-țabīj fì-l-Magrib wa al-Andalus fí 'așr al-Muwaḥhidīn. (La cocina hispano magrebí en la época almohade según un manuscrito anónimo del siglo XIII). Madrid: Maestre.

Huici Miranda, A. 2005. La cocina hispano-magrebi durante la época almohade según un manuscrito anónimo del siglo XIII. Gijón: Ediciones Trea. Reedición, con estudio preeliminar de Manuela Marín.

Lafuente, P. 1996. "La cocción de los alimentos. Aproximación al menaje de cocina en una casa islámica (S. XIII)". Arqueología Medieval 4: 175-182.

Lerchundi, J. 1892. Vocabulario español-arábigo del dialecto de Marruecos.Tánger: Misión Católica. Reedición, Madrid: AECI. 1999.

Leriche, A. 1953. "De l'origine du thé au Maroc et au Sahara". Bulletin de l'Institut de l'Afrique Noire XV (4): 371-375.

Marín, M. 1999. "Ollas y fuego: los procesos de cocción en los recetarios de al-Andalus y el Magreb". Arqueología Medieval 4: 165-174.

M'Hamsadji, N. 1955. "Le matériel de cuisine dans les régions d'Aumale et de SidiAïssa". Annales de l'Institut d'Études Orientales XIII: 5-29.

Monod, Th. 1955. "Sur la forme de la théière maure traditionnelle". Notes africaines 67: $71-72$.

Mulero Clemente, M. 1945. Los territorios españoles del Sahara y sus grupos Nómadas. Las Palmas de Gran Canaria: Domingo Sánchez Talavera.

Oro Pulido, A. del. 1940. Algo sobre el Hasanía o dialecto que se habla en el Sabara Atlántico. Tánger: Alta Comisaría de España en Marruecos, Delegación de Asuntos Indígenas.

Ould Mohamed Baba, A. S. 1996. "Refranero en dialecto árabe ḥassāniya". Anaquel de Estudios Árabes 7: 145-240.

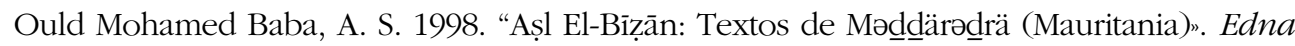
3: 163-201.

Ould Mohamed Baba, A. S. 2002. "El dialecto hassāniyya de el-Gebla: Textos para su estudio". Edna 6: 233-251.

Ould Mohamed Baba, A. S. 2004. "Los berberismos del dialecto árabe hassāniyyä de elGəblä». Anaquel de Estudios Árabes 15: 175-184.

Ould Mohamed Baba, A. S. 2007. "Las isoglosas léxicas del dialecto árabe hassāniyyä". Anaquel de Estudios Árabes 18: 191-200

Ould Mohamed Baba, A. S. 2008. Refranero y fraseología hassani. Recopilación, explicación, estudio gramatical y glosario. Serie Estudios Árabes e Islámicos. Subserie Estudios de Dialectología Árabe 2. Zaragoza: Instituto de Estudios Islámicos y del Oriente Próximo.

Rennes-Taizin, A. 1978. Opposition d'aspect et expression du temps dans le dialecte de hassaniyya de Mauritanie, Mémoire de maîtrise sous la direction de D. Cohen, Univiversité de Paris III.

Rosselló Godoy, G. 1994. "Arqueología e información textual: el utillaje en la cocina andalusí", en Marín, M. y Wines, D. (eds.), La alimentación en las culturas islámicas: 37-87. Madrid: AECI. 
Taine-Cheikh, C. 1978. "Bibliographie linguistique sur le hassaniyya", en Inventaire des Études Linguistiques sur les pays d'Afrique noire d'expression française et sur Madagascar: 263-278. París: C.I.L.F.

Taine-Cheikh, C. 1988. "Les diminutifs dans le dialecte arabe de Mauritanie". Al-Wasit 2: 89-118.

Taine-Cheikh, C. 1988-98. Dictionnaire hassaniyya-français. (8 vols. Publicados hasta la letra Fâ). París: Geuthner.

Taine-Cheikh, C. 1997. "Les emprunts au berbère Zénaga. Un sous-système vocalique du hassāniyya". Mas-Gellas 8: 93-142.

Ṭäleb Buya, L. 1999. Šadāâât min al-adab al-ḥassānī. Rabat: Éditions Markaz Ṭareq Bin Zayyād lid-dirāsāti wal-abḥāt.

Volpato, G. 2008. Plantas medicinales saharaui. Holanda: Universidad de Wageningen.

Fecha de recepción: 19 de julio de 2014

Fecha de aceptación: 18 de noviembre de 2014 